УДК: $316.7(075.8)$

$10.17213 / 2075-2067-2020-6-275-281$

\title{
ДЕСЕКУЛЯРИЗАЦИЯ В РОССИЙСКОМ ОБЩЕСТВЕ: ПРЕДПОСЫЛКИ И ПРОЯВЛЕНИЯ
}

\author{
(C) 2020 г. A. В. Матецкая
}

\section{Южнный федеральный университет, г. Ростов-на-Дону, Россия}

Цель исследования. Статья посвящена изучению предпосылок десекуляризации в российском обществе и основных проявлений этого проиесса.

Методология исследования основывается на концепџиях модернизаџии, секуляризаичи и десекуляризации, применяются методы сравнительного и исторического анализа.

Результаты исследования. Прочесс десекуляризачии начинается задолго до распада СССР, отправной точкой этого процесса можно считать ограниченную легализацию религии, осуществленную государством в годы Великой Отечественной войныл. Однако десекуляризачия в советский период не сводилась лишь к разрешению традиционным религиозным организациям функционировать на законных основаниях, хотя и в очень узких пределах. Она включала обращение крелигиозной проблематике в сфере культурного творчества и культурной деятельности, а также оживление религиозных и мировоззренческих исканий в советском обществе в 60-80-е годы ХХ века. Позднесоветское и постсоветское возрождение религии не возникло внезапно, но представляло собой развитие и разрастание десекуляризационных тенденций, начавшихся в советском обществе еще в середине XX века, несмотря на продолжавшуюся политику ограничения религиозной деятельности и атеистического воспитания.

Перспективы использования результатов исследования. Результаты исследования могут использоваться в дальнейшем изучении религиозной динамики российского общества.

Ключевые слова: религия; сочииология религии; культура; секуляризация; десекуляризаичи; Русская православная церковь; нетрадиционная религиозность.

\section{DESECULARISATION IN RUSSIAN SOCIETY: PREREQUISITES AND MANIFESTATIONS}

\section{(C) 2020 A. V. Matetskaya}

\section{Southern Federal University, Rostov-on-Don, Russia}

Purpose of the study. The paper is devoted to the study of the preconditions for desecularization in Russian society and the main manifestations of this process.

The research methodology is based on the concepts of modernization, secularization and desecularization.

Results of the study. The process of de-secularization began long before the collapse of the Soviet Union, and its starting point was the limited legalization of religion, which was carried out by the state during the Great Patriotic War. However, desecularization in the Soviet period was not limited to allowing traditional religious organizations to operate legally, albeit within very narrow limits. It also included a later reference to religious issues in the sphere of cultural 
creativity and cultural activity and a revival of religious and ideological quests in Soviet society in the 1960s-80s. The late-Soviet and post-Soviet religious revival did not occur all of a sudden, but was a development and expansion of the desecularisation processes which had begun in Soviet society in the mid-20th century, despite the continuing policy of restricting religious activity and atheistic education.

Prospects for the use of the results of the study. The results of the study can be used in the further study of religious dynamics in Russian society.

Key words: religion; sociology of religion; culture; secularization; desecularization; Russian Orthodox Church; non-traditional religiousness.

Введение. Во второй половине XX века происходит осознание ограниченности доминирующей в социологии религии парадигмы секуляризации. Исследователи столкнулись с фактом сохранения и даже активизации религиозности практически во всем мире $[1,2]$. Наиболее заметными проявлениями религиозного возрождения стали политизация ислама, активизация глобальной миссионерской деятельности протестантских, в основном неопятидесятнических деноминаций; возникновение в результате иммиграции в секулярных европейских обществах заметного мусульманского меньшинства; возрождение религии в странах бывшего социалистического лагеря; развитие новой или альтернативной религиозности и/или духовности [3]. Реальность пришла в противоречие с теорией, основанной, как оказалось, не только на фактическом, но и на идеологическом фундаменте. Концепция секуляризации была подвергнута критическому осмыслению [4]. В результате возник ряд новых теоретических подходов и понятий, а концепция секуляризации оказалась не столько отвергнутой, сколько уточненной.

Теоретический аспект. Понятие десекуляризации было предложено П. Бергером [5], одним из наиболее влиятельных теоретиков секуляризации, пересмотревшим свои позиции. Несмотря на то, что понятие десекуляризации стало довольно употребительным, оно не имеет общепринятого определения и зачастую используется как интуитивно ясное. Карпов справедливо отмечает: «Удивительно мало усилий прикладывалось до сих пор к тому, чтобы концептуализировать десекуляризацию и эвристически использовать это тео- ретическое понятие в сравнительных исследованиях возрождения религий в современном мире. Более того, сам термин “десекуляризация" использовался редко и по большей части без прояснения его значения, как если бы это понятие было самоочевидным» [6, с. 115]. Основываясь на идеях Бергера, Карпов понимает десекуляризацию как реакцию на секуляризационные изменения (как «контрсекуляризацию»), но при этом отмечает, что и понимание секуляризации не единообразно.

Обращаясь к работе Х. Казановы о публичной религии [7], он выделяет вслед за ним три аспекта секуляризации, которые не всегда скоординированы между собой. Во-первых, секуляризация как дифференциация, отделение религии от других социальных институтов и главное - от государства. Во-вторых, секуляризация как уменьшение влияния религии, ее ослабление, упадок традиционных практик. В-третьих, приватизация религии. Если десекуляризация - это реакция на секуляризацию, то можно выделить три ее направления: «(а) сближение между некогда секуляризованными институтами и религиозными нормами, (b) возрождение религиозных верований и практик и (c) возвращение религии в публичную сферу. В данном случае важно отметить, что контрсекуляризационные процессы могут быть слабо связаны или совсем не связаны друг с другом, так же как и вышеупомянутые секуляризационные тенденции» [6, с. 124].

К выделенным возможным направлениям десекуляризации Карпов добавляет также десекуляризацию в сфере культуры, в пространстве смыслов. Секуляризация проявлялась как раз в том, что в смысловом и символическом пространстве современ- 
ных обществ религия занимала все меньше места, теснимая научным мировоззрением, светской философией, светскими идеологиями, светским искусством, светской моралью и т.д. Если использовать выражение теолога Х. Кокса [8], секуляризация вела к профанизации жизни, человек эпохи модерна был обитателем «профанного града», он не был врагом религии, он просто в ней не нуждался для ориентации в мире. То, что последствия «профанизации» культуры (т.е. выветривания из нее религиозного духа) оказались преувеличенными, не говорит о том, что этот процесс вообще не имел места. Реакцией на секуляризацию культуры является возвращение в культурное пространство религиозных идей, образов и символов.

Концепция секуляризации не была отброшена в результате критики, но была скорректирована: вышеперечисленные аспекты секуляризации наблюдаемы в тех обществах, где секуляризация имела место. Ю. Хабермас, говоря об уточнении «тезиса секуляризации», отмечал: «Споры по поводу социологического тезиса о секуляризации привели к пересмотру, прежде всего, прогностических утверждений. С одной стороны, религиозная система стала более дифференцированной и в значительной степени утратила другие функции. С другой стороны, нет глобальной связи между модернизацией общества и растущей утратой значения религии, которая была бы настолько тесной, что мы могли бы рассчитывать на исчезновение религии» [9].

Парадоксальность современной религиозной ситуации в мире в целом и в отдельных государствах заключается в одновременном протекании как секуляризационных, так и десекуляризационных процессов.

Отечественный вариант десекуляризации. Десекуляризация является реакцией на секуляризацию, а секуляризация, как и модернизация, вариативна. Осознание множественности моделей секуляризации стало одним из аспектов уточнения секуляризационной парадигмы. Отечественная модель секуляризации значительно отличалась от западной модели и в европейском, и в американском ее вариантах. Можно сказать, что до начала социалистических преобразований российская секуляризация развивалась в форме, сходной с европейской, хотя и не тождественной ей. Но формирование советского государства и советской власти, основанных на специфической идеологии (такой тип идеологии будет позже назван политической религией), создало для секуляризации иные условия. Победившая идеология не допускала существования религии, видя в ней пережиток прошлого и мировоззренческого соперника, от которого было необходимо избавиться. Европейская модель секуляризации подразумевала стихийный процесс отделения религии от других институтов, нарастающий мировоззренческий плюрализм и приватизацию религии. Советская модель подразумевала подавление религии и в перспективе - ее уничтожение. Советская власть не ограничивалась идейной борьбой с религией, хотя и это было важно и являлось государственным делом. Подавление религии включало: лишение религиозных организаций собственности, преследование и нередко физическое уничтожение духовенства и активных мирян, сведение к минимуму возможностей для религиозного образования и религиозной социализации в семье, устранение религии из каких-либо позитивных смысловых контекстов, агрессивное навязывание атеистического мировоззрения, сведение деятельности религиозных организаций только к исполнению религиозных обрядов и т.д.

При всем размахе антирелигиозной борьбы значительная часть населения сохранила религиозные верования, хотя верующие были почти лишены возможности участвовать в богослужениях, не говоря уже о других возможных формах активности за пределами собственно совершения ритуалов. Наиболее стойкие верующие образовали религиозное подполье, рискуя ради веры не только благополучием, но и жизнью. Публичное же пространство, как и официальная культура, были полностью очищены от влияния традиционных религий — их место заняла победившая тотальная идеология.

Изменение отношения советского государства к религии произошло в годы войны, когда власти понадобилось мобилизовать все ресурсы для достижения победы, в том числе и моральные ресурсы. Н. Митрохин отмечает: «Последовавшее после 1943 года сталинское "религиозное возрождение" дало 
возможность воссоздания деятельности ряда традиционных для Российской империи религиозных общин. Однако государство тщательно контролировало границу между легализованной религиозностью старших по возрасту, малообразованных социальных групп и советизированным “образованным классом”. Кроме того, оно жестко разделило религиозную деятельность на санкционированную (то есть узкий круг зарегистрированных религиозных организаций, официально подконтрольных Совету по делам РПЦ и Совету по делам религиозных культов) и нелегальную» [10]. Несмотря на крайне ограниченный характер этого «возрождения», именно оно послужило началом десекуляризации. Традиционные религии, в первую очередь, Русская православная церковь (как наиболее крупная религиозная организация в советском обществе), получили возможность контролируемого, зависимого, но все же легального существования. Церковь была восстановлена как социальный институт и использовалась советским государством для решения внутриполитических и внешнеполитических задач. Тем не менее, религиозность продолжала оставаться для советских граждан запретной деятельностью, особенно религиозность, не связанная с дозволенными формами религиозной активности. Необходимость скрывать религиозную принадлежность порождала «гиперприватизацию» религии [11]. По-прежнему ограниченные возможности для религиозного образования и получения информации о религии, почти полное отсутствие религии в публичном пространстве вели к снижению культурного уровня большинства верующих. Но нарастающий кризис официальной идеологии, постепенное смягчение репрессивности режима способствовали оживлению духовных и религиозных поисков, что служило предпосылкой дальнейшего развития десекуляризационных процессов, уже не связанных напрямую с государственной политикой. Десекуляризация не ограничивалась восстановлением запрещенных или уничтоженных религиозных практик, но подразумевала также появление новых форм религиозности и духовности. Одним из важных факторов, стимулирующих религиозный и мировоззренческий поиск, был рост уровня образования советских людей. Средой распространения религиозных идей стала советская интеллигенция, численность которой увеличивалась в результате распространения высшего образования. В первую очередь в этой среде распространялись и старые, и новые религиозные идеи и практики.

Культура и религия. В 60 -е годы XX века в развитии советской культуры возникают новые тенденции, связанные с ростом интереса к культурному наследию и укреплению исторической памяти. Символической точкой отсчета этого процесса можно считать основание в 1965 году «Всероссийского общества по охране памятников истории и культуры». При этом в других национальных республиках подобные общества возникли даже раньше, что приводило представителей российской творческой интеллигенции к сетованиям по поводу того, что именно российское культурное наследие находится в наиболее тяжелом положении.

В 60-е годы возникает, по выражению Корминой и Штыркова, идеология советского ретроспективизма [12]. Если в более ранний период существования советского режима было принято подчеркивать разрыв с прошлым, новизну создаваемого социалистического общества, то теперь становится необходимым говорить о связи настоящего с прошлым.

Историческое прошлое превращается в источник для укрепления коллективной идентичности и мировоззренческого поиска. Памятники религиозной культуры - уцелевшие храмы, религиозное искусство становятся объектом изучения, восстановления и музеификации. Знакомство с ними считается важным элементом воспитания. При этом рецепция религиозного наследия имеет целью не религиозное обращение, а формирование культурного и образованного человека, помнящего о своих корнях. Однако знакомство с религиозным наследием часто становилось превращенной и легитимной формой интеpeca к религии как таковой. Легитимация интереса к религиозному наследию позволила использовать религиозную проблематику в литературе, искусстве и кино, что в свою очередь приводило к расширению представ- 
лений о религии в советском общественном сознании, хотя атеизм, превратившийся в атеизм научный, продолжал оставаться доминирующим элементом советской идеологии.

Кормина и Штырков отмечают: «Религия, пока в виде объектов, возвращается в советскую публичную сферу, но только в новом статусе: как часть советского сакрального культуры - и во многих контекстах культуры национальной (национальной святыни). Ответственными за эту сферу были особые специалисты, именуемые деятелями и работниками культуры. Деятели - это публичные интеллектуалы, такие как академик Д. С. Лихачев, создававшие своими текстами советский канон, работники - профессионалы, работавшие в учреждениях культуры, прежде всего в домах культуры и музеях, и занимавшиеся пропагандой и воплощением идеологического канона» $[12$, с. 14].

Нетрадиционная религиозность и духовность. Важной составляющей десекуляризации в советский период было распространение среди интеллигенции различных видов новой религиозности и паранаучных идей, нередко имевших квазирелигиозный характер. Составляющими элементами этого пестрого комплекса идей и верований были восточные религии (прежде всего, индуизм и буддизм), наследие европейского и российского мистицизма и эзотеризма, интерес к НЛО, парапсихологии, феноменам типа «снежного человека», ко всему «таинственному и необычному», не имеющему объяснения в рамках «современного научного знания». Часто подобные идеи разделялись представителями официальной науки, а также культурной и политической элитой.

Интерес к нетрадиционной духовности в советском обществе практически совпал хронологически с возникновением движения Нью Эйдж и всплеском нетрадиционной религиозности в западных обществах. Советская нетрадиционная религиозность была не столько результатом культурного заимствования, сколько следствием сходной исторической ситуации: повышения уровня жизни и образования и мировоззренческого кризиса, связанного с недоверием не только к политическим идеологиям, но и к традиционным формам религии.
Заключение. Начало десекуляризации российского общества было связано со смягчением репрессивной антирелигиозной политики в годы Великой Отечественной войны. В советской десекуляризации можно выделить три аспекта. Во-первых, это институциональное восстановление и легализация подавляемых ранее религиозных организаций. Во-вторых, проникновение религиозных идей, образов и символов в официальную советскую культуру в результате нового подхода к религиозному наследию - оно стало восприниматься как элемент национального культурного наследия, которое следовало изучать, сберегать и передавать следующим поколениям. Парадоксальным образом секуляризация религиозного наследия посредством превращения его в культурную ценность способствовала десекуляризации, поскольку легитимировала присутствие религии в публичном пространстве и в светском образовании. В-третьих, распространение альтернативной духовности и новых религиозных течений. В постсоветский период все эти тенденции получили дальнейшее развитие, а десекуляризация приобрела гораздо больший масштаб.

\section{Литература}

1. Гафиатулина Н.Х., Самыгин С.И. Религиозные установки как элемент управления ценностными ориентациями современной молодежи // Экономические проблемы России и региона. Ученые записки. Ростовский государственный экономический университет (РИНХ). - Ростов-на-Дону, 2019. C. 217-225.

2. Kasyanov V.V., Belikova N. Y., Krotov D. V., Samygin S. I., Merzakanov S. A. Religious orientations of modern youth and the national policy// Advances in Intelligent Systems and Computing. - 2020. - Vol. 1100 AISC. - P. 601-613.

3. Белов М. Т., Гафиатулина Н.Х., Самьгин С.И. Управление религиозными ориентирами в сознании современной молодежи // Экономические проблемы России и региона. Ученые записки. Ростовский государственный экономический университет (РИНХ). Ростов-на-Дону, 2019. - С. 186-193.

4. Shakhbanova M.M., Velikorodnaya I.V., Starostin A.M., Tishkin D.N., Samygin S.I. The 
factors of escalaion of ethno-political tension in the south of Russia // Public Administration and Regional Management in Russia. Challenges and Prospects in a Multicultural Region. Ser. «Contributions to Economics». - Switzerland, 2020. - P. 405-415.

5. Berger P.L. The Desecularization of the World: A Global Overview // The Desecularization of the World: Resurgent Religion and World Politics / Ed. Peter L. Berger. - Grand Rapids: William B. Eerdmans Publishing Company, 1999.

6. Карпов В. Концептуальные основы теории десекуляризации // Государство, религия, церковь в России и за рубежом. 2012. 一 №2 (30). - C. 114-164.

7. Casanova J. Public Religions in the Modern World. - Chicago: The University of Chicago Press, 1994.

8. Кокс $X$. Мирской град: секуляризация и урбанизация в теологическом аспекте. СПб.: Восточная литература, 1995. - 262 с.

9. Habermas $J$. A postsecular world society? An interview with Jürgen Habermas (2010). [Electronic resource]. — URL: https://tif.ssrc. org/2010/02/03/a-postsecular-world-society/.

10. Митрохин H. Советская интеллигенция в поисках чуда: религиозность и паранаука в СССР в 1953-1985 годах [Электронный ресурс] // Новое литературное обозрение. - 2020. - №3 (163). - Режим доступа: https://www.nlobooks.ru/magazines/novoe literaturnoe_obozrenie/163_nlo_3_2020/ article/22225/.

11. Шишков А. Некоторые аспекты десекуляризации в постсоветской России // Государство, религия, церковь в России и за рубежом. - 2012. — №2 (30). — С. 165-177.

12. Кормина Ж., Штырков С. «Это наше исконно русское и никуда нам от этого не деться»: предыстория постсоветской десекуляризации // Изобретение религии: десекуляризация в постсоветском контексте. - СПб.: Издательство Европейского университета, 2015. $-280 \mathrm{c}$.

\section{References}

1. Gafiatulina N.H., Samygin S.I. Religioznye ustanovki kak jelement upravlenija cennostnymi orientacijami sovremennoj molodezhi [Religious attitudes as an element of management of value orientations of modern youth] // Jekonomicheskie problemy Rossii i regiona. Uchenye zapiski. Rostovskij gosudarstvennyj jekonomicheskij universitet (RINH) [Economic problems of Russia and the region. Scientific notes. Rostov State University of Economics (RSUE)]. — Rostov-on-Don, 2019. - Pp. 217-225.

2. Kasyanov V.V., Belikova N. Y., Krotov D. V., Samygin S. I., Merzakanov S. A. Religious orientations of modern youth and the national policy// Advances in Intelligent Systems and Computing. - 2020. - Vol. 1100 AISC. - P. 601-613.

3. Belov M.T., Gafiatulina N.H., Samygin S. I. Upravlenie religioznymi orientirami v soznanii sovremennoj molodezhi [Management of religious landmarks in the consciousness of modern youth] // Jekonomicheskie problemy Rossii i regiona. Uchenye zapiski. Rostovskij gosudarstvennyj jekonomicheskij universitet (RINH) [Economic problems of Russia and the region. Scientific notes. Rostov State University of Economics (RSUE)]. - Rostov-on-Don, 2019. - Pp. 186-193.

4. Shakhbanova M.M., Velikorodnaya I.V., Starostin A.M., Tishkin D. N., Samygin S.I. The factors of escalaion of ethno-political tension in the south of Russia // Public Administration and Regional Management in Russia. Challenges and Prospects in a Multicultural Region. Ser. «Contributions to Economics». - Switzerland, 2020. - P. 405-415.

5. Berger P.L. The Desecularization of the World: A Global Overview // The Desecularization of the World: Resurgent Religion and World Politics / Ed. Peter L. Berger. - Grand Rapids: William B. Eerdmans Publishing Company, 1999.

6. Karpov V. Konceptual'nye osnovy teorii desekuljarizacii [Conceptual foundations of the theory of desecularization] // Gosudarstvo, religija, cerkov' v Rossii i za rubezhom [State, religion, Church in Russia and abroad]. - 2012. №2 (30). - Pp. 114-164.

7. Casanova J. Public Religions in the Modern World. - Chicago: The University of Chicago Press, 1994.

8. Koks $H$. Mirskoj grad: sekuljarizacija i urbanizacija $\mathrm{v}$ teologicheskom aspekte [Mirsky Grad: Secularization and Urbanization in the theological aspect]. - Saint-Petersburg: Vostochnaja literatura, $1995 .-262 \mathrm{p}$.

9. Habermas $J$. A postsecular world society? An interview with Jürgen Habermas (2010). 
[Electronic resource]. — URL: https://tif.ssrc. org/2010/02/03/a-postsecular-world-society/.

10. Mitrohin N. Sovetskaja intelligencija v poiskah chuda: religioznost' i paranauka v SSSR V 1953-1985 godah [Soviet intelligentsia in search of a miracle: religiosity and paranauka in the USSR in 1953-1985] [Jelektronnyj resurs] // Novoe literaturnoe obozrenie [New Literary Review]. — 2020. — №3 (163). — URL: https:// www.nlobooks.ru/magazines/novoe_literaturnoe_obozrenie/163_nlo_3_2020/article/22225/.

11. Shishkov A. Nekotorye aspekty desekuljarizacii v postsovetskoj Rossii [Some aspects of desecularization in post-Soviet Russia] //
Gosudarstvo, religija, cerkov' v Rossii i za rubezhom [State, religion, Church in Russia and abroad]. — 2012. — №2 (30). — Pp. 165-177.

12. Kormina Zh., Shtyrkov $S$. «Jeto nashe iskonno russkoe $\mathrm{i}$ nikuda nam ot jetogo ne det'sja»: predystorija postsovetskoj desekuljarizacii [ «This is our native Russian and we can't get away from it anywhere»: prehistory of postSoviet desecularization] // Izobretenie religii: desekuljarizacija $\mathrm{v}$ postsovetskom kontekste [The Invention of Religion: Desecularization in a post-Soviet context]. — Saint-Petersburg: Izdatel'stvo Evropejskogo universiteta, 2015. $-280 \mathrm{p}$.

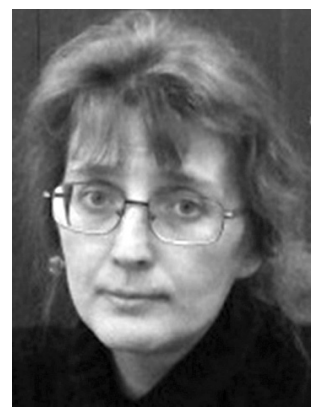

Матецкая Анастасия Витальевна - доктор философских наук, доцент, профессор кафедры философии религии и религиоведения Южного федерального университета.

Matetskaya Anastasia Vitalyevna - Doctor of Philosophical Sciences, Professor, Department of Philosophy of Religion and Religious Studies, Southern Federal University.

344065, г. Ростов-на-Дону, пер. Днепровский, 116 116 Dneprovsky ln., 344065, Rostov-on-Don, Russia E-mail: tojgar@mail.ru 